\title{
Time-Dependent Changes in Cocaine-Seeking Behavior and Extracellular Dopamine Levels in the Amygdala during Cocaine Withdrawal
}

\author{
Ly T.L. Tran-Nguyen, Ph.D., Rita A. Fuchs, M.A., Greg P. Coffey, B.S., David A. Baker, M.A.,
} Laura E. O'Dell, Ph.D., and Janet L. Neisewander, Ph.D.

Cocaine and cocaine-associated cues elicit craving in addicts and reinstate cocaine-seeking behavior in rats. Craving and cocaine-seeking behavior may be mediated by withdrawalinduced changes in dopamine (DA) neurotransmission in the amygdala. To examine whether there are concomittant changes in cocaine-seeking behavior and extracellular DA levels during withdrawal, experimental rats were trained to self-administer cocaine $(0.75 \mathrm{mg} / \mathrm{kg} \mathrm{IV})$. After 14 daily 3-hour training sessions, animals underwent either a 1-day, 1-week, or 1-month withdrawal period. Extracellular DA levels were assessed during baseline, extinction, cue reinstatement, and cocaine $(15 \mathrm{mg} / \mathrm{kg} I P)$ reinstatement of cocaine-seeking behavior (i.e., defined as the difference in nonreinforced lever presses on an active minus inactive lever). Cocaine-seeking behavior became more intense during the course of cocaine withdrawal. Additionally, basal and cocaine-induced extracellular DA levels were enhanced after the 1-month withdrawal period. We suggest that the former may reflect a persistent elevation in tonic extracellular DA levels in the amygdala, whereas the latter may reflect a persistent elevation in phasic extracellular DA levels. [Neuropsychopharmacology 19:48-59, 1998] (C) 1998 American College of Neuropsychopharmacology. Published by Elsevier Science Inc.
KEY WORDS: Craving; Cocaine-seeking behavior; Cocaine withdrawal; Dopamine; Amygdala; Reinstatement;

Extinction; Self-administration

Craving is thought to play a critical role in drug relapse (Dackis and Gold 1985; Gawin and Kleber 1986; Wallace 1989). Gawin and Kleber (1986) have suggested that early during withdrawal from a cocaine binge there is little or no craving, and that later during withdrawal there is intense craving that can be exacerbated by cocaine-paired cues. In the laboratory, addicts exposed to drug-related cues (Childress et al. 1988; Ehrman et al. 1992; Satel et

From the Department of Psychology, Arizona State University, Box 871104, Tempe, AZ.

Address correspondence to: Janet L. Neisewander, Ph.D., Department of Psychology, Arizona State University, Box 871104, Tempe, AZ 85285-1104.

Received September 11, 1997; revised November 7, 1997; accepted November 13, 1997. al. 1995) or given a cocaine priming injection report intense craving (Jaffe et al. 1989; Kosten et al. 1992; Preston et al. 1993) and exhibit conditioned physiological changes (Ehrman et al. 1992). Similarly, animals with a history of cocaine self-administration exhibit reinstatement of extinguished cocaine-seeking behavior after presentation of cocaine-paired cues or a cocaine priming injection (Davis and Smith 1976; Stewart 1984; Stewart et al. 1984). In these studies, cocaine-seeking behavior is measured as nonreinforced lever-pressing behavior.

Reinstatement of cocaine-seeking behavior may be mediated by enhanced dopamine (DA) neurotransmission because systemic administration of indirect (Gerber and Stretch 1975; de Wit and Stewart 1981; Worley et al. 1994) or direct DA receptor agonists (de Wit and Stewart 1981; Wise et al. 1990; Self et al. 1996) reinstates cocaine-seeking behavior. It has been suggested based on localization studies that the nucleus accumbens (NAc) is involved because drugs that enhance DA neu- 
rotransmission in this region reinstate cocaine-seeking behavior (Stewart 1984). Studies have also examined conditioned DA neurotransmission in the NAc after presentation of cocaine-paired cues, but the results have been controversial. After presentation of a light paired previously with cocaine self-administration, in vivo voltammetry studies have demonstrated that putative DA-related signals increase in the NAc (Gratton and Wise 1994; Kiyatkin and Stein 1994; Kiyatkin 1995), whereas an in vivo microdialysis study indicated no changes in extracellular DA levels (Neisewander et al. 1996). Electrophysiological studies have demonstrated a change in neuronal firing in the NAc prior to cocainereinforced lever pressing (Chang et al. 1994; Carelli and Deadwyler 1994, 1996; Peoples and West 1996). This anticipatory response may be DA mediated in some (Carelli and Deadwyler 1996), but not all cells (Chang et al. 1994). Furthermore, Fontana et al. (1993) found a context-dependent sensitization of both locomotor behavior and extracellular DA levels in the NAc after a cocaine challenge in a cocaine-paired environment, whereas Brown and Fibiger (1992) found conditioned locomotion, but no conditioned increase in extracellular DA levels after a saline challenge. Finally, exposure to a cocaine-paired environment failed to alter Fos levels in the NAc (Brown et al. 1992).

Another approach for investigating the role of DA in cocaine-seeking behavior is to examine whether timedependent changes in DA neurotransmission during withdrawal correspond to changes in cocaine-seeking behavior. Across studies using self-administration regimens, findings indicate time-dependent changes in both basal and cocaine-induced extracellular DA levels in the NAc. Basal extracellular DA levels in the NAc are maximally depressed within 4 to 6 hours after unlimited access cocaine self-administration regimens (Weiss et al. 1992a,b; Parsons et al., 1995). With 3-hour access self-administration regimens, basal extracellular DA levels in the NAc are typically enhanced early during withdrawal (i.e., 1 to 5 days; Weiss et al. 1992a,b; Parsons et al. 1995) and return to control levels later during withdrawal (i.e., 7 to 21 days; Hooks et al. 1994; Meil et al. 1995; Neisewander et al. 1996). Furthermore, cocaine-induced extracellular DA levels are unaltered after 1 day (Hurd et al. 1989; Hooks et al. 1994; Meil et al. 1995), decreased after 7 days (Meil et al. 1995; Neisewander et al. 1996), and increased after 21 days of withdrawal (Hooks et al. 1994) from 3-hour access selfadministration regimens. It is unclear whether a similar pattern of changes occurs in other DA terminal regions and whether these time-dependent changes in DA are involved in cocaine-seeking behavior.

The amygdala is another mesolimbic DA terminal that may play a role in reinstatement of cocaine-seeking behavior. Fos levels are enhanced in the amygdala after exposure to a cocaine-paired environment (Brown et al.
1992). Furthermore, amygdala lesions disrupt conditioned reinforcement (Cador et al. 1989; Everitt et al. 1989; Burns et al. 1993), psychostimulant conditioned place preference (Hiroi and White 1991; Brown and Fibiger 1993), and cue reinstatement of cocaine-seeking behavior (Meil and See 1997). In addition, these lesions disrupt acquisition of cocaine-seeking behavior under a second-order, but not continuous, schedule of reinforcement (Whitelaw et al. 1996). Disruption of DA neurotransmission in the amygdala also attenuates the rewarding and discriminative stimulus properties of psychostimulants (McGregor and Roberts 1993; McGregor et al. 1994; Caine et al. 1995; Callahan et al. 1995).

The present study examined whether there are timedependent changes in extracellular DA levels in the amygdala after withdrawal from a cocaine self-administration regimen, and whether these changes correspond to changes in cocaine-seeking behavior during extinction, cue reinstatement, and cocaine reinstatement of cocaine-seeking behavior. Cocaine-seeking behavior and extracellular DA levels were measured after a 1-day, 1-week, or 1-month withdrawal period.

\section{MATERIALS AND METHODS}

\section{Subjects and Design}

Adult male Sprague-Dawley rats, weighing 275 to $325 \mathrm{~g}$ at the start of the experiment, were housed individually in a colony room with a 12-hour light-dark cycle (lights on at 6:00 A.M. lights off at 6:00 P.M.). The animals were handled for 5 days before starting the experiment. They were randomly assigned to an experimental group that received response-contingent cocaine infusions or a saline-yoked control group that received an equal volume of saline contingent upon the responses made by an experimental animal. Experimental animals were randomly assigned to groups tested for cocaine-seeking behavior and extracellular DA levels in the amygdala after a 1-day $(n=8), 1$-week $(n=12)$, or 1-month $(n=$ 10) withdrawal period from self-administration. Salineyoked controls were also tested at these time points. No differences were found among controls tested at different times, and therefore, their data were combined to comprise a single control group $(n=11)$.

\section{Food Training}

Animals were given restricted access to food (i.e., 1 hour/day) for 2 days before training and throughout the food training process. Animals were placed into an operant chamber $(24 \times 27 \times 31 \mathrm{~cm}$; Coulbourn Instruments, Lehigh, PA) that was equipped with a lever, a food tray located $2 \mathrm{~cm}$ to the right of the lever, and a houselight located directly above the food tray. They were trained to lever press for a food pellet $(45 \mathrm{mg}$; 
Noyes, Lancaster, NH) initially on a fixed ratio 1 (FR 1) schedule and progressing to a variable interval 10 (VI 10) schedule across 5 days. Food training was implemented to facilitate subsequent cocaine self-administration training, which occurred in different operant chambers. After food training was completed, animals were given free access to food for 1 to 2 days before undergoing surgery.

\section{Surgery}

Animals were anesthetized with sodium pentobarbital (50 mg/kg IP; Sigma Chemical Co., St. Louis, MO) in conjunction with atropine sulfate $(10 \mathrm{mg} / \mathrm{kg}$ IP; Sigma Chemical Co., St. Louis, MO), then catheters were implanted into the jugular vein as described by Depoortere et al. (1993). Briefly, the catheters were constructed from a piece of silastic tubing $\left(10 \mathrm{~cm}\right.$; I.D. $0.012^{\prime \prime} \times$ O.D. 0.025"; Dow Corning, Midland, MI) that was attached to a bent 22-gauge metal cannula. During surgery, incisions were made across the head to expose the skull and in the neck to expose the jugular vein. A burrow was made subcutaneously from the neck to the head, and the metal cannula of the catheter was threaded through the burrow. A small incision was made in the jugular vein, and the silastic tubing was inserted and then secured to the vein with sutures. Next, the animals were stereotaxically implanted with 23-gauge guide cannulae aimed bilaterally at the amygdala (AP $-2.2 \mathrm{~mm}$ and $\mathrm{ML} \pm 4.8 \mathrm{~mm}$ from bregma with bregma and lambda horizontal; Paxinos and Watson 1986). The guide cannulae and the metal cannula of the catheter were cemented to the skull. Throughout the experiment, the catheters were flushed daily with a solution of $0.1 \mathrm{ml}$ saline, heparin sodium (10 U/ml; Elkins-Sinn Inc., Cherry Hills, NJ), streptokinase $(0.67 \mathrm{mg} / \mathrm{ml}$; Astra Pharmaceutical Products, Westerborough, MA), and ticarcillin disodium $(66.67 \mathrm{mg} / \mathrm{ml}$; SmithKline Beecham Pharmaceuticals, West Chester, PA) to maintain patency. Intravenous methohexital sodium (Eli Lilly \& Co., Indianapolis, IN) tests were performed periodically throughout the study to verify catheter patency (i.e., $0.08 \mathrm{mg}$ methohexital sodium briefly anesthetizes the animals only when administered IV).

\section{Self-Administration Training}

Cocaine self-administration training began 5 days after surgery. Daily 3-hour sessions of self-administration training were given for 14 consecutive days during the animals' light cycle between 8:00 A.M. and 5:00 P.M. Animals were placed into an operant chamber $(20 \times 28 \times$ $20 \mathrm{~cm}$; Med Associates, St. Albans, VT) that was equipped with an active lever, a cue light located $4 \mathrm{~cm}$ above the active lever, an inactive lever located on the opposite wall, a tone generator, and a houselight located 10 $\mathrm{cm}$ above the inactive lever in the center of the wall. Initially, experimental animals were placed on an FR 1 schedule of cocaine reinforcement $(0.75 \mathrm{mg} / \mathrm{kg} / 0.1 \mathrm{ml}$ infusion). After animals obtained 20 reinforcers on a given day, the schedule was changed to a variable ratio (VR) 2 schedule, and then finally to a VR 5 schedule of reinforcement. Schedule completions by experimental animals on the active lever resulted in inactivation of the houselight and activation of the cue light, tone (2.9 $\mathrm{KHz}, 10 \mathrm{~dB}$ above background noise), and 1 second later the infusion pump, which delivered a 6-second infusion of cocaine. Immediately after the infusion was delivered, all cues were inactivated. After a 20 -second timeout period, the houselight was reactivated. Responding on the inactive lever had no scheduled consequences. Animals in the control group received the same stimulus complex and a 0.1-ml infusion of saline contingent upon schedule completions by the experimental animal. Several studies have demonstrated that food deprivation facilitates drug self-administration behavior (Carroll et al. 1981; de la Garza and Johanson 1987). Thus, to facilitate acquisition of cocaine self-administration behavior, animals were deprived of food before the onset of the dark cycle the evening before the first session. They remained on a 1-hour restricted feeding schedule until they began responding on the VR 5 schedule of reinforcement during the self-administration sessions. In addition, animals that failed to respond within $10 \mathrm{~min}$ were given priming infusions $(0.75 \mathrm{mg} /$ $\mathrm{kg}$ ) every 2 to 3 minutes for a maximum of three infusions per session. Priming infusions were not administered during the last 4 days of training.

\section{Dialysis Probes and Probe Implantation}

Dialysis probes were constructed as described by Robinson and Camp (1991). The probes consisted of a 2-mm effective length of cellulose dialysis membrane (maximum MW of 5,000-6,000, O.D. $233 \mu \mathrm{m}$, I.D. $215 \mu \mathrm{m}$, membrane thickness $18 \mu \mathrm{m}$; Spectra/Por Spectrum Medical, Laguna Hills, CA) with a 0.25-mm epoxy plug at the tip. In vitro recovery of DA ranged from $10 \%$ to $25 \%$.

At least 22 hours before testing, animals were lightly anesthetized with ketamine $(19 \mathrm{mg} / \mathrm{kg}$ IM; Fort Dodge Co., Fort Dodge, IA) and xylazine (6 mg/kg IM; Lloyd Laboratories, Shenandoah, IA) and were implanted with microdialysis probes aimed at the amygdala. The probes were implanted through the guide cannulae to a depth of $9.5 \mathrm{~mm}$ from the skull and were secured to the skull using dental acrylic cement. The inlet and outlet tubings from the probes were threaded through a coiled steel tether. The inlet tubings were attached to a dual channel liquid swivel commutator above the tether, and the outlet tubings were inserted into collection vials attached to the tether and located above the top of the chamber. Collection vials were easily exchanged with- 
out interfering with the animals' behavior. A flexible steel wire protruding from the headmount was connected to the tether to relieve tension from the inlet and outlet lines of the probe. After implantation, animals were placed back into their homecages and were transferred to the colony room. Ringer's solution $(128.3 \mathrm{mmol} / \mathrm{L} \mathrm{NaCl}$, $1.35 \mathrm{mmol} / \mathrm{L} \mathrm{CaCl}_{2}, 2.68 \mathrm{mmol} / \mathrm{L} \mathrm{KCl}$, and $2.0 \mathrm{mmol} / \mathrm{L}$ $\mathrm{MgCl}_{2}, \mathrm{pH} 7.3 \pm 0.05$ ) was continuously pumped through the probes overnight at a rate of $0.15 \mu \mathrm{l} / \mathrm{min}$.

\section{Dialysate Measures during Extinction and Reinstatement of Cocaine-Seeking Behavior}

Testing began 22 hours after probe implantation during the animals' light cycle between 8:00 A.M. and 5:00 P.M. Throughout testing, fresh Ringer's solution was pumped at a rate of $1 \mu \mathrm{l} / \mathrm{min}$ through the probes. Three consecutive 20-minute baseline samples were collected while animals remained in their homecages in the colony room. Subsequently, animals were transported to the testing room and, after a 30-minute adaptation period, three additional samples were collected. Extracellular DA levels in the amygdala and cocaine-seeking behavior were then assessed during three consecutive phases: (1) extinction, (2) cue reinstatement, and (3) cocaine reinstatement. The extinction phase began immediately after the animals were transferred to the operant chambers. The houselight was illuminated and responses on the previously active lever had no scheduled consequences. After 2 hours, the cue reinstatement phase began by presentation of the stimulus light and tone paired previously with cocaine. These cues were activated for 7 -second periods alternating with 20 -second time-out periods to resemble the response-contingent presentation of the cues during self-administration training. Two hours later, the cocaine reinstatement phase began by administration of a priming injection of cocaine $(15 \mathrm{mg} / \mathrm{kg} \mathrm{IP})$ to all animals. During this phase, the houselight was illuminated and no other cues were presented. This test phase ended 2 hours later. Responses on both levers were recorded and 20-minute dialysate samples were collected throughout behavioral testing. Samples were collected into vials containing $20 \mu \mathrm{l}$ of a perchloric acid solution (PAS; containing $0.00001 \%$ of $1 \mathrm{~mol} / \mathrm{L} \mathrm{Na}_{2} \mathrm{~S}_{2} \mathrm{O}_{5}$ and $0.001 \%$ of 0.2 mol/L EDTA) to stabilize DA. They were immediately frozen on dry ice and stored at $-70^{\circ} \mathrm{C}$ until assayed.

\section{Assay of Dialysate}

HPLC-EC was used to assay dialysis samples. Approximately $40 \mu \mathrm{l}$ of sample (20 $\mu$ l of dialysate collected into $20 \mu \mathrm{l}$ of PAS) were injected onto a 5-cm Rainin catecholamine HR 80 reverse-phase column ( $3 \mu \mathrm{m}$ C18 particles $4.6 \mathrm{~mm}$ I.D.; Rainin Instruments, Woburn, MA). The mobile phase consisted of $60 \mathrm{mmol} / \mathrm{L} \mathrm{NaH}_{2} \mathrm{PO}_{4}, 30$ $\mathrm{mmol} / \mathrm{L}$ citric acid, $0.1 \mathrm{mmol} / \mathrm{L}$ EDTA, $20 \mathrm{mg} / \mathrm{L}$ SDS, and $15 \% \mathrm{MeOH}$, at a $\mathrm{pH}$ of 3.0. The HPLC-EC system consisted of an ESA Model 420 dual piston pump, a Model 5200 Coulochem II detector, and a Model 5021 conditioning cell positioned in front of a dual electrode Model 5014A high sensitivity analytical cell (Bedford, MA). The conditioning cell was set to oxidize at $100 \mathrm{mV}$ to reduce background noise. The reduction of DA was quantified at the second electrode set to $-350 \mathrm{mV}$ with a filter setting of 10 seconds. The total elution time ranged from 6 to 15 minutes. Peak heights were recorded on an Alltech Linear Model 1200 dual pen recorder with a chart speed setting of $20 \mathrm{~cm} /$ hour with both maximum pen deflections equivalent to $1 \mathrm{~V}$. Peaks of a standard consisting of $4 \mathrm{pg} / \mu \mathrm{l}$ of DA were used to calculate the concentration of DA in the samples based on linear regression analyses. DA levels were corrected for efficiency of probe recovery.

\section{Histology}

Animals were killed 24 hours after completion of the experiment. Probe placements in the amygdala were subsequently verified from $20-\mu \mathrm{m}$ coronal sections stained with cresyl violet.

\section{Data Analysis}

Analyses of variance (ANOVAs) were used to analyze dialysate DA and cocaine-seeking behavior (i.e., nonreinforced lever presses on the active lever minus the inactive lever) during acquisition, extinction, and reinstatement testing with group (control, 1-day, 1-week, or 1-month withdrawal) as a between-subjects factor and 20-minute interval as a repeated measure. One-way ANOVAs were used to analyze mean basal extracellular DA levels and total cocaine-seeking behavior for the three phases and total number of priming infusions during self-administration training. Significant main effects and interactions were further analyzed using Fisher LSD tests. Correlations between cocaine-seeking behavior and extracellular DA levels during the three test phases, and between cocaine-seeking behavior and the total number of priming infusions during selfadministration training were performed followed by $t$-test for significance of the correlation coefficients.

\section{RESULTS}

\section{Probe Placements}

The approximate placement of the dialysis probes in the amygdala from all animals included in this study is illustrated in Figure 1. In each case, the majority of the 2-mm effective length of each probe was located within the basolateral or central amygdaloid nuclei. 


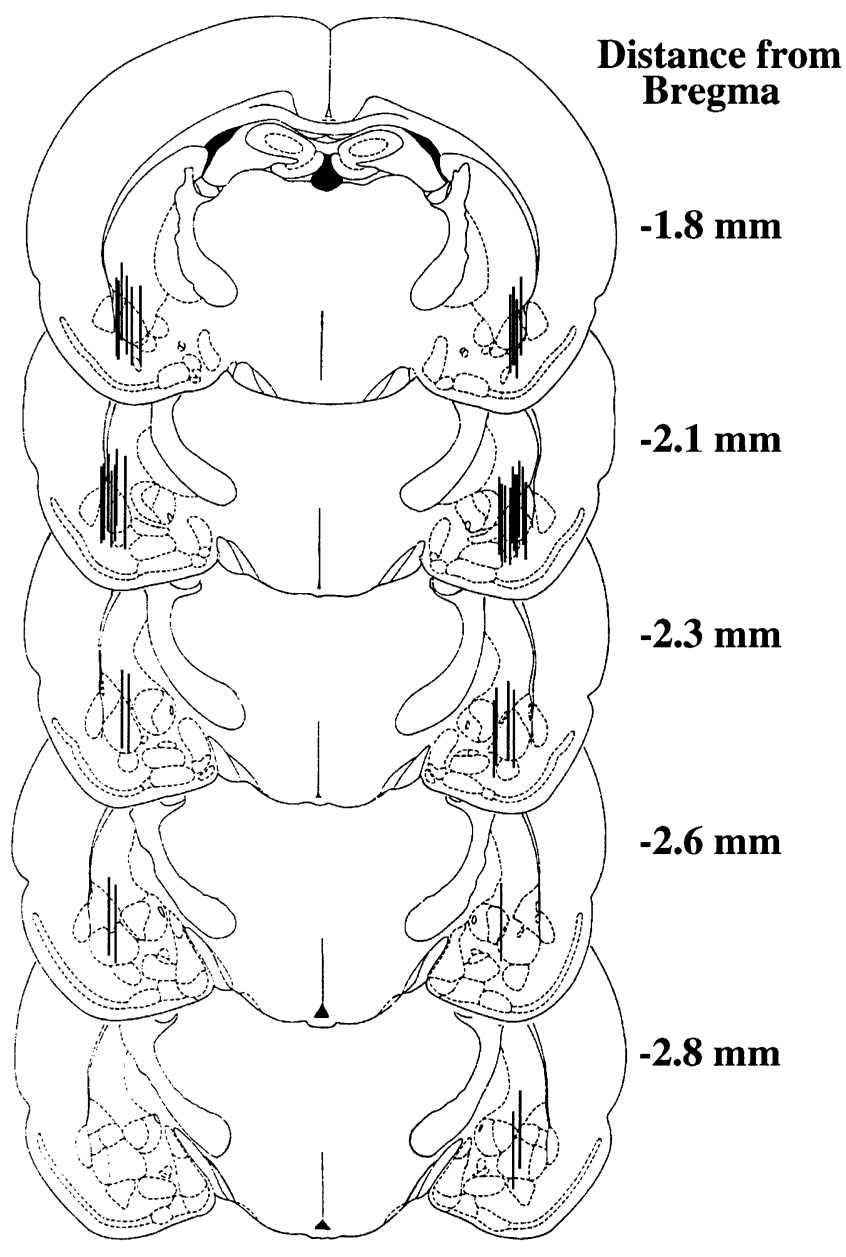

Figure 1. Approximate placements of the effective length of the dialysis probe membranes. The majority of the 2-mm effective membrane of each probe was located in the basolateral or central amygdaloid nuclei. Drawings were adapted from illustrations in the Paxinos and Watson (1986) atlas.

\section{Cocaine Intake during Self-Administration Training}

An analysis of the mean number of cocaine infusions ( \pm SEM) across the 14 daily 3-hour self-administration sessions indicated that there were no significant differences in cocaine intake between the cocaine groups $(\mathrm{F}[2,26]=1.9, \mathrm{NS}$; data not shown $)$. The average daily intake of cocaine was $7.6 \pm 1.0 \mathrm{mg}$.

\section{Baseline Extracellular DA Levels}

Dialysate collected in the colony room represents the baseline (BL) overflow for each group. An analysis of the mean of the three 20-minute BL samples indicated that the 1-month withdrawal group exhibited an increase in extracellular DA levels relative to the control and 1-week withdrawal groups $(\mathrm{F}[3,34]=3.2, p<.05$; Fisher LSD, $p<.05$; Figure 2). The 1-day withdrawal group also exhibited an increase in BL extracellular DA levels; however, this increase was not significantly higher than controls nor significantly lower than the 1-month withdrawal group. In addition, a trend analysis of mean BL data from the cocaine-experienced groups indicated a significant U-shaped quadratic trend $(\mathrm{F}[1,34]=10.64, p<.01)$.

\section{Extracellular DA Levels in the Self-Administration Room}

An analysis of the mean of the three 20-minute samples collected in the self-administration room indicated that the 1-month withdrawal group exhibited an increase in extracellular DA levels relative to all other groups $(\mathrm{F}[3,34]=5.9, p<.005$; Fisher LSD,$p<.05$; data not shown). In addition, to best reflect changes in extracellular DA levels after transfer to the self-administration room, fmol/min change from BL was analyzed (see Figure 3B). The overall ANOVA indicated a strong trend toward a group difference $(\mathrm{F}[3,34]=2.7, p<.06)$, which appeared to be due to an increase in extracellular DA levels in the 1-month withdrawal group relative to the control and 1-week withdrawal groups (Fisher LSD, $p<.05)$.

\section{Cocaine-Seeking Behavior and Extracellular DA Levels during Extinction}

Cocaine-seeking behavior was defined as the number of nonreinforced lever presses on the active minus the inactive levers (difference score). Cocaine-seeking behavior across time during the extinction and reinstatement test phases is illustrated in Figure 3A, and the total amount of cocaine-seeking behavior for each phase is illustrated in Figure 4A. During the extinction phase,

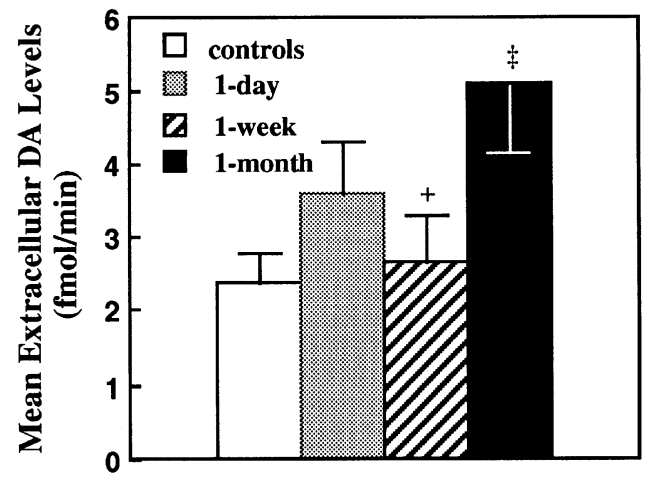

Figure 2. Mean BL extracellular DA levels ( \pm SEM) from samples collected in the colony room. Double daggers $(\ddagger)$ represent a significant difference from the control group (Fisher LSD, $p<.05$ ); and plus signs $(+)$ represent a significant difference from the 1-month withdrawal group (Fisher $\mathrm{LSD}, p<.05)$. 


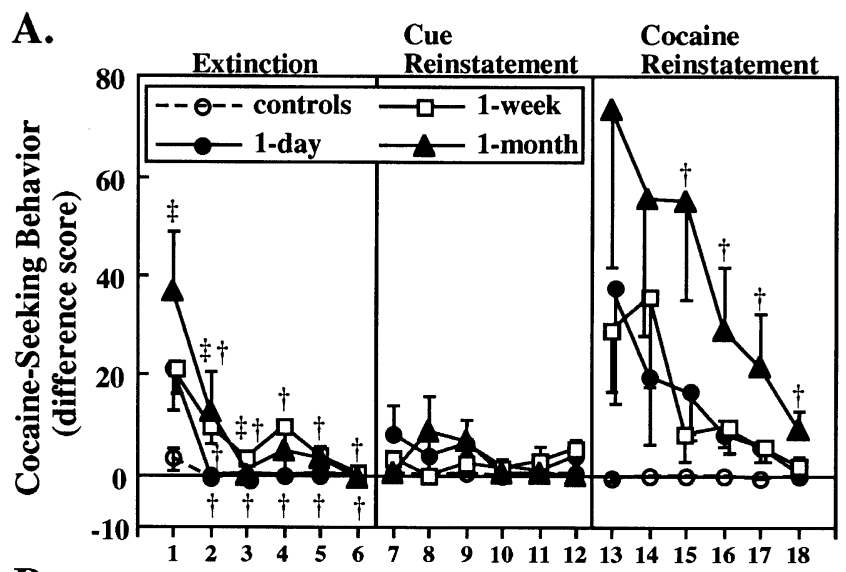

B.

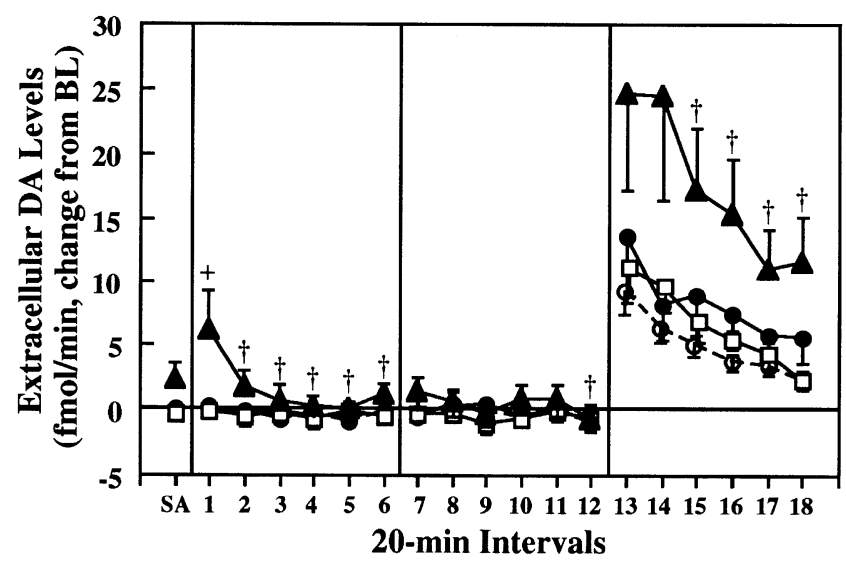

Figure 3. (A) Cocaine-seeking behavior expressed as a difference in lever presses on the inactive lever from lever presses on the active lever (difference score \pm SEM) and (B) extracellular DA levels expressed as $\mathrm{fmol} / \mathrm{min}$ change from BL values ( \pm SEM); following transfer to the self-administration room (SA) and across time during the extinction and reinstatement phases. The extinction phase began immediately after placement of the animals into the operant chambers. Two hours later, the cue reinstatement phase began by presentation of the light and tone paired previously with cocaine infusions. Two hours later, the cocaine reinstatement phase began by administration of a priming injection of cocaine $(15 \mathrm{mg} / \mathrm{kg} \mathrm{IP})$. Double daggers ( $)$ represent a significant difference from the control group (Fisher LSD, $p<.05$ ); daggers $(t)$ represent a significant difference from the first 20-minute interval of a test phase for individual groups during the extinction phase and collapsed across groups during the cocaine reinstatement phase (Fisher LSD, $p<.05$ ); and plus signs $(+)$ represent a significant difference from selfadministration room measure (Fisher LSD, $p<.05$ ).

cocaine-experienced animals exhibited cocaine-seeking behavior after being placed into the operant chambers, and this behavior gradually extinguished by the end of the phase. The overall ANOVA of cocaine-seeking behavior across time during extinction revealed a significant group by 20 -minute interval interaction $(\mathrm{F}[15,180]=$ $2.0, p<.05)$. The 1-month withdrawal group exhibited
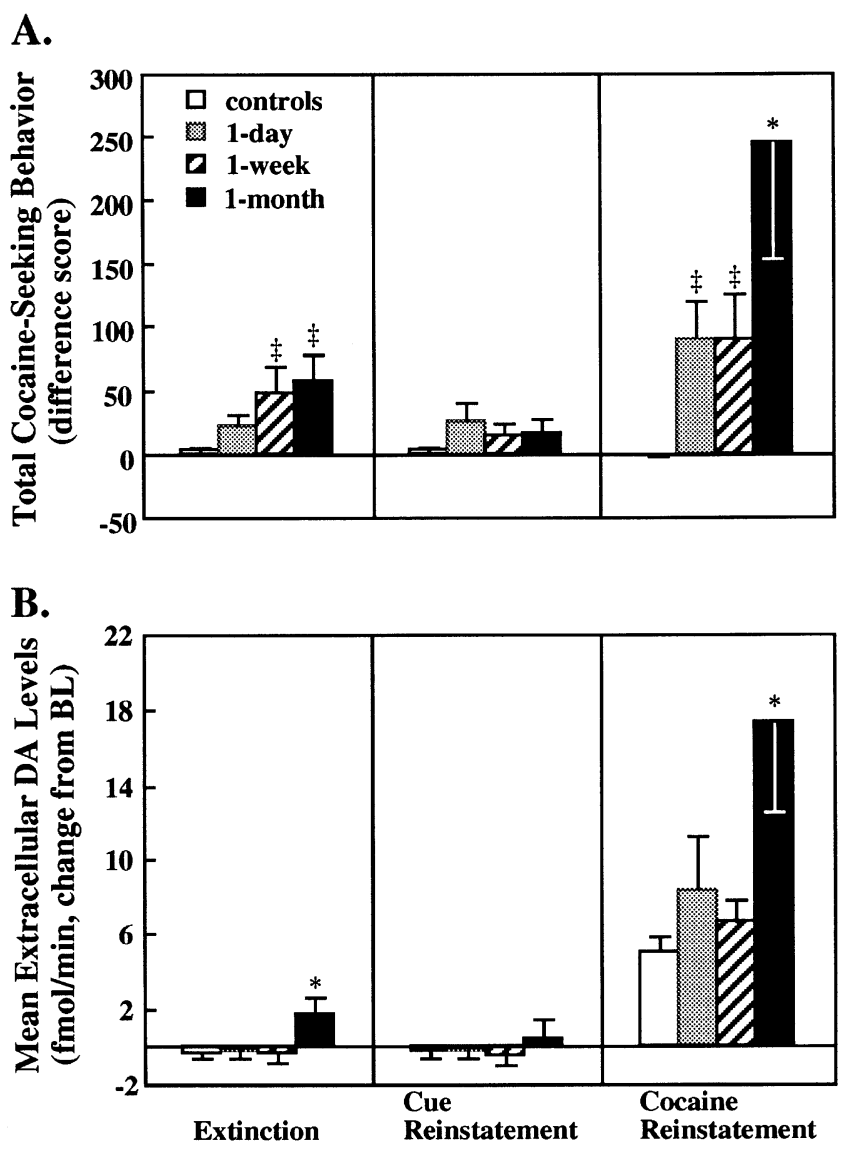

Figure 4. (A) Total cocaine-seeking behavior (difference score \pm SEM) and (B) mean extracellular DA levels collapsed across 20-minute intervals ( \pm SEM); during the extinction and reinstatement phases. The test phases are described in Figure 3. Double daggers $(\ddagger)$ represent a significant difference from the control group (Fisher LSD, $p<.05$ ); and astrisks $\left(^{*}\right)$ represent a significant difference from all other groups (Fisher LSD, $p<.05$ ).

significantly more cocaine-seeking behavior than the control group during intervals 1 and 2 (Fisher LSD, $p<$ $.05)$, whereas the 1-week withdrawal group exhibited significantly more cocaine-seeking behavior than the control group during interval 3 (Fisher LSD, $p<.05$; Figure 3A left). An analysis of total cocaine-seeking behavior during the extinction phase indicated a significant main effect of group $(\mathrm{F}[3,36]=3.1, p<.05)$. The 1 -week and 1-month withdrawal groups exhibited significantly more cocaine-seeking behavior than the control group (Fisher LSD, $p<.05$; Figure 4A left).

To best reflect changes in extracellular DA levels associated with each test phase, $\mathrm{fmol} / \mathrm{min}$ change from BL was analyzed. Alterations in change from BL DA levels were observed during the extinction phase depending on the withdrawal period. Repeated measures analysis of change from BL DA levels in the self-administration room and DA levels during the first interval of the extinction phase revealed a significant group by re- 
peated measures interaction $(\mathrm{F}[3,34]=3.1, p<.05)$. The 1-month withdrawal group exhibited a significant increase in extracellular DA levels during the first 20-minute interval of extinction (Fisher LSD, $p<.05$; Figure $3 \mathrm{~B}$ ), whereas the other groups did not exhibit a significant change in extracellular DA levels. Furthermore, the overall ANOVA of extracellular DA levels across time during the extinction phase revealed a main effect of group $(\mathrm{F}[3,34]=3.7, p<.05)$ and 20-minute interval $(\mathrm{F}[5,170]=3.0, p<.05)$, but no group by 20 minute interval interaction. Subsequent analysis of the main effect of group indicated that the 1-month withdrawal group exhibited a significant enhancement in extracellular DA levels relative to all other groups (Fisher LSD, $p<.05$; Figure 4B left). Subsequent analysis of the main effect of 20-minute interval indicated that extracellular DA levels were significantly greater during the first 20-minute interval relative to subsequent intervals, regardless of group (Fisher LSD, $p<$ .05; Figure 3B left).

\section{Cocaine-Seeking Behavior and Extracellular DA Level during the Cue Reinstatement Phase}

The overall ANOVA of cocaine-seeking behavior across time during the cue reinstatement phase revealed that there were no significant differences between groups, nor across 20-minute intervals (Figure $3 \mathrm{~A}$ middle). In addition, cocaine-experienced animals did not exhibit a change in extracellular DA levels in the amygdala relative to the control animals after presentation of the stimulus complex. An analysis of extracellular DA levels across time during the cue reinstatement phase revealed only a significant main effect of 20-minute interval $(\mathrm{F}[5,170]=2.9, p<.05)$. Extracellular DA levels during interval 6 were significantly lower relative to interval 1 regardless of group (Fisher LSD, $p<.05$; Figure 3B middle).

\section{Cocaine-Seeking Behavior and Extracellular DA Levels during the Cocaine Reinstatement Phase}

During the cocaine reinstatement phase, cocaine-experienced animals exhibited cocaine-seeking behavior after receiving a priming injection of cocaine that gradually declined over time (Figure $3 \mathrm{~A}$ right). The overall ANOVA of cocaine-seeking behavior across time revealed a main effect of group $(\mathrm{F}[3,36]=4.7, p<.01)$ and 20 -minute interval $(\mathrm{F}[5,180]=5.8, p<.0001)$, but no group by 20 -minute interval interaction. The cocaineexperienced groups exhibited cocaine-seeking behavior that gradually declined by interval 3 relative to interval 1 (Fisher LSD, $p<.05$ ). An analysis of total cocaineseeking behavior during the cocaine reinstatement phase indicated that the 1-month withdrawal group exhibited significantly more cocaine-seeking behavior than all other groups (Fisher LSD, $p<.05$ ). Surprisingly, there were no other significant differences among the groups. However, this was due to the high amount of variability in the 1-month withdrawal group obscuring between-group differences (see Figure 4A right; MS error $=21,112)$. An ANOVA without this group revealed a significant main effect of group (MS error $=6,813$; $\mathrm{F}[2,28]=4.23, p<.05)$, and subsequent pairwise comparisons revealed that the 1-day and 1-week withdrawal groups exhibited significantly more cocaine-seeking behavior than controls (Fisher LSD, $p<.05$ ).

Similarly, all animals exhibited an increase in extracellular DA levels immediately after the priming injection of cocaine which gradually declined over time (Figure $3 \mathrm{~B}$ right). The overall ANOVA of extracellular DA levels across time revealed a main effect of group $(\mathrm{F}[3,34]=4.0, p<.05)$ and 20-minute interval $(\mathrm{F}[5,170]=$ $19.0, p<.0001$ ), but no group by 20-minute interval interaction. Similar to the time course of cocaine-seeking behavior, cocaine-induced DA levels were significantly attenuated by interval 3 relative to interval 1 (Fisher LSD, $p<.05$ ). An analysis of mean DA dialysate indicated that the 1-month withdrawal group exhibited a significant increase in extracellular DA levels relative to all other groups (Fisher LSD, $p<.05$; Figure $4 \mathrm{~B}$ right).

\section{Relationship between Cocaine-Seeking Behavior and Extracellular DA Levels during the Extinction and Reinstatement Phases}

There were no significant correlations between cocaineseeking behavior (total difference score) and extracellular DA levels (mean change from BL) collapsed across time during any of the three phases when all animals with a history of cocaine self-administration were included in the analysis (data not shown). Similarly, no significant correlations were found between these variables during any 20-minute interval of any test phase (data not shown). The lack of a significant relationship between cocaine-seeking behavior and extracellular DA levels in the amygdala may be due to a lack of statistical power.

\section{Cocaine-Seeking Behavior and Noncontingent Priming Infusions during Self-Administration Training}

Eighty-one percent of the animals in the cocaine groups received noncontingent priming infusions of cocaine $(0.75 \mathrm{mg} / \mathrm{kg} / 0.1 \mathrm{ml})$ during the first 10 days of selfadministration training. Twenty percent of these animals received priming infusions of cocaine on day 10 of training, although none were primed for 10 consecutive days. An analysis of the total number of noncontingent priming infusions of cocaine during self-administration training indicated no differences among the cocaine- 
experienced groups $[\mathrm{F}(2,24)=2.08$, NS; data not shown $]$. However, there was a significant positive correlation between the total number of priming infusions and cocaine-seeking behavior (total difference score) during the cocaine reinstatement phase $\left(\mathrm{r}_{\mathrm{xy}}=0.40, p<.05\right)$. No significant correlations were found during the extinction and cue reinstatement phases.

\section{DISCUSSION}

There are three new findings from the present study. These data provide the first demonstration of timedependent enhancement of cocaine-seeking behavior (i.e., operationally defined as nonreinforced lever pressing on the active minus inactive lever) during the course of cocaine withdrawal in an animal model of relapse. Specifically, during the extinction phase the 1-week and 1-month withdrawal groups exhibited more cocaineseeking behavior than the control and 1-day withdrawal groups. Furthermore, during the cocaine reinstatement phase, all cocaine-experienced groups exhibited more cocaine-seeking behavior than the control group, and this behavior was more robust in the 1-month withdrawal group relative to the other groups. Contrary to the latter finding, Erb et al. (1996) reported no differences in cocaine reinstatement of cocaine-seeking behavior in animals tested at 1 to 2 weeks and again at 4 to 6 weeks of withdrawal. Because Erb et al. (1996) utilized a within-subjects design, the lack of enhanced cocaineseeking behavior at the later time point may be due to repeated experience with extinction. Furthermore, the dose and route of administration of the priming injection of cocaine differed across these studies. Thus, it is possible that the testing parameters used in the present study were more sensitive for detection of time-dependent changes in cocaine-seeking behavior.

Cocaine-seeking behavior during extinction and cue reinstatement testing is thought to reflect incentive motivation for cocaine. Indeed, the time-dependent enhancement of cocaine-seeking behavior in animals undergoing longer withdrawal periods in the present study (i.e., 1 week to 1 month) parallels the temporal pattern of craving observed in cocaine addicts. Addicts experience little or no craving early after a cocaine binge; however, later during the course of withdrawal they experience intense craving that can be exacerbated by cocaine or cocaine-paired cues (Gawin and Kleber 1986). Thus, the present findings provide support for the validity of the extinction/reinstatement model of craving.

During cocaine reinstatement testing, however, two explanations for cocaine-seeking behavior can be offerred. First, cocaine reinstatement of cocaine-seeking behavior may reflect incentive motivation for cocaine. Incentive motivation for cocaine is thought to increase with longer withdrawal periods (Robinson and Ber- ridge 1993). Furthermore, repeated passive administration of cocaine is thought to sensitize incentive motivational processes. Thus, the enhanced cocaine-seeking behavior in the 1-month withdrawal group, as well as the correlation between passively administered priming infusions and cocaine-seeking behavior, are consistent with this interpretation. A second interpretation for cocaine reinstatement of cocaine-seeking behavior is that the priming infusions of cocaine administered during training may have acquired discriminative stimulus properties that signal the availability of cocaine reinforcement, thereby reinstating cocaine-seeking behavior (Di Chiara 1995; Carroll and Comer 1996). The correlation between priming infusions and cocaine-seeking behavior is also consistent with this interpretation because animals receiving more priming infusions should exhibit a greater degree of discrimination learning. However, discriminative stimulus control over responding cannot account for the time-dependent differences in cocaine-induced cocaine-seeking behavior because there was no difference in the number of priming infusions received during self-administration training across withdrawal groups. Furthermore, several arguments mitigate the discriminative stimulus explanation. First, 19\% of the animals in the cocaine groups did not receive any priming injections during self-administration training, yet these animals exhibited cocaine reinstatement of cocaine-seeking behavior. This finding indicates that discriminative stimulus control is not necessary for cocaine reinstatement of cocaine-seeking behavior. Second, the IV priming infusions administered during self-administration training likely produce different stimulus properties than the IP priming injection given during testing. Third, one would expect the memory for the cocaine discriminative stimulus to be stronger early during withdrawal, resulting in more cocaine-seeking behavior relative to later during withdrawal. However, the opposite pattern was observed in the present study. Finally, the time-dependent enhancement of cocaine-seeking behavior during cocaine reinstatement was similar to that observed during extinction (i.e., enhanced at longer withdrawal periods), suggesting that both may involve incentive motivation. Although these arguments do not eliminate the discriminative stimulus interpretation, it seems likely that the passive administration of the priming infusions sensitized incentive motivation for cocaine.

The second new finding from this study was that basal extracellular DA levels changed in a time-dependent manner. Specifically, basal extracellular DA levels were enhanced in the 1-month withdrawal group relative to the control and 1-week withdrawal groups. Extracellular DA levels in the 1-day withdrawal group were also elevated, but were not significantly different from any other group. Dialysate measures of basal DA are thought to reflect extracellular DA levels from tonic re- 
lease that is involved in maintaining homeostasis (Grace 1995). Thus, the time-dependent change in basal extracellular DA levels suggests that regulation of tonic extracellular DA levels in the amygdala changes during the course of withdrawal from cocaine self-administration.

The third new finding was that cocaine-induced extracellular DA levels were enhanced depending on the withdrawal period. Specifically, during the cocaine reinstatement phase, all groups exhibited a significant enhancement of extracellular DA levels relative to baseline that was more robust in the 1-month withdrawal group than in the other groups. Cocaine-induced extracellular DA levels likely reflect DA from tonic and phasic release, because cocaine inhibits the reuptake of DA, and therefore, may allow diffusion of synaptic DA levels from phasic release into the extrasynaptic space to be detected by in vivo microdialysis (Grace 1995). Thus, the present findings are consistent with the idea that cocaine-induced DA neurotransmission becomes sensitized after longer withdrawal periods.

The pattern of changes in DA neurotransmission in the amygdala and cocaine-seeking behavior observed in the present study varied depending on the test phase. During the extinction phase, the 1-week and 1-month withdrawal groups both exhibited an increase in cocaine-seeking behavior, but only the 1-month withdrawal group exhibited an increase in extracellular DA levels. In contrast, during the cocaine reinstatement phase, all cocaine-experienced groups exhibited an increase in cocaine-seeking behavior and extracellular DA levels, and both measures were more robust in the 1-month withdrawal group than the 1-day and 1-week withdrawal groups. It is possible that changes in DA in the amygdala may not be involved in cocaine-seeking behavior. Alternatively, it is possible that changes in DA in the amygdala may be involved in cocaine reinstatement of cocaine-seeking behavior, but are not involved in reinstatement by a cocaine-paired environment. If this is the case, then other neurotransmitters in the amygdala are likely involved, because lesions of this structure disrupt cue reinstatement of cocaine-seeking behavior (Meil and See 1997) and acquisition of cocaineseeking behavior under a second-order schedule of reinforcement (Whitelaw et al. 1996). DA neurotransmission in the amygdala may mediate cocaine-seeking behavior after a priming injection of cocaine given that changes in these variables corresponded during the cocaine reinstatement phase. Consistent with this idea, it has been suggested that blockade of DA neurotransmission in the amygdala attenuates the rewarding effects of psychostimulants (McGregor and Roberts 1993; McGregor et al. 1994; Caine et al. 1995) and disrupts the discriminative stimulus properties of cocaine (Callahan et al. 1995). Another reason DA neurotransmission may be involved in reinstatement of responding by the priming injection of cocaine is that DA-mediated stereotypic behavior may manifest as repeated lever pressing. The latter seems unlikely, however, because stereotypies induced by intracranial self-stimulation or cocaine typically occur between bouts of self-administration behavior and are not directed at the reinforced lever (Wise et al. 1977; Chang et al. 1994).

An alternative explanation for the discrepancy in the pattern of cocaine-seeking behavior and extracellular DA levels in the amygdala across the test phases may be that in vivo microdialysis is more sensitive to detect phasic changes after the priming injection (i.e., cocaine reinstatement phase) than testing under normal physiological conditions (i.e., extinction phase). During the extinction phase, the elevated basal extracellular DA levels in the 1-month withdrawal group may have increased the sensitivity to detect conditioned phasic DA release in this group relative to other groups. In addition, cocaine administered at the onset of the reinstatement phase increased extracellular DA, thereby increasing the sensitivity to detect phasic extracellular DA levels in all groups (Grace 1995). Consistent with this idea, conditioned DA release in the NAc is detected after a cocaine, but not a saline, challenge in a cocainepaired environment (Brown and Fibiger 1992; Fontana et al. 1993).

Lastly, it is possible that the enhanced extracellular DA levels observed late during the course of withdrawal (i.e., 1-month withdrawal group) may be due to a withdrawal-induced increase in sensitivity to stress associated with handling and changing environmental conditions during testing. Consistent with this idea, stressors, such as restraint, footshock, and tail-pinch, can increase self-administration of psychostimulants (Piazza et al. 1990; Ramsey and Van Ree 1993; Goeders and Guerin 1994) and opioids (Shaham 1993; Shaham et al. 1993; Shaham and Stewart 1994, 1995). Furthermore, psychostimulant-induced locomotion is cross-sensitized by previous experience with stressors (Sorg and Kalivas 1991; Prasad et al. 1995), and both psychostimulants and stressors increase extracellular DA levels in the NAc (Kalivas and Stewart 1991; Sorg and Kalivas 1991; Prasad et al. 1995; Shaham and Stewart 1995). Thus, cross-sensitization to stressors may emerge during the course of cocaine withdrawal and may underlie the overall enhancement in extracellular DA levels observed in the 1-month withdrawal group across all test phases.

In the present study, an attempt was made to demonstrate that presentation of discrete cues (i.e., tone and light) paired previously with cocaine infusions gain incentive motivational value sufficient to reinstate cocaine-seeking behavior. Unfortunately, the lack of cue reinstatement in the present study precluded an interpretation of the relationship between extracellular DA levels and cue reinstatement of cocaine-seeking behavior. Previous research from our laboratory has dem- 
onstrated a modest, but significant reinstatement of cocaine-seeking behavior using a similar procedure (Fuchs et al. in press). The reason cocaine-seeking behavior was not observed during the cue reinstatement phase may have been due to hangover effects from the anesthetic administered for probe implantation. Other laboratories have also demonstrated that cue reinstatement of drug-seeking behavior is not very robust (de Wit and Stewart 1981; Weissenborn et al. 1995), although preliminary results from our laboratory indicate that cue reinstatement is enhanced by less frequent cue presentation (i.e., every 5 minutes versus presentation every 20 seconds as in the present study; unpublished observation). Further research is needed to elucidate the relationship between extracellular DA levels in the amygdala and cue-reinstatement of cocaine-seeking behavior.

\section{ACKNOWLEDGMENTS}

We are grateful to Drs. Kathy Matt, Peter Killeen, and Craig Nagoshi for their review of an earlier version of this manuscript. We are also grateful to Sam Leifheit, Thomas Shepherd, Lewis Bizo, and Taline Khroyan for their technical assistance. This research was supported by USPHS grants DA07730 and DA11064, a grant from the Howard Hughes Medical Institute through the Undergraduate Biological Science Education Program, and the NIMH/Minority Neuroscience Training Program.

\section{REFERENCES}

Brown EE, Fibiger HC (1992): Cocaine-induced conditioned locomotion: Absence of associated increases in dopamine release. Neuroscience 48:621-629

Brown EE, Fibiger HC (1993): Differental effects of excitotoxic lesions of the amygdala on cocaine-induced conditioned locomotion and conditioned place preference. Psychopharmacology 113:123-130

Brown EE, Robertson GS, Fibiger HC (1992): Evidence for conditional neuronal activation following exposure to a cocaine-paired environment: Role of forebrain limbic structures. J Neurosci 12:4112-4121

Burns LH, Robbins TW, Everitt BJ (1993): Differential effects of excitotoxic lesions of the basolateral amygdala, ventral subiculum and medial prefrontal cortex on responding with conditioned reinforcement and locomotor activity potentiated by intra-accumbens infusion of D-amphetamine. Behav Brain Res 55:167-183

Cador M, Robbins TW, Everitt BJ (1989): Involvement of the amygdala in stimulus-reward associations: Interaction with the ventral striatum. Neuroscience 30:77-86

Caine SB, Heinrichs SC, Coffin VL, Koob GF (1995): Effects of the dopamine D-1 antagonist SCH 23390 microinjected into the accumbens, amygdala or striatum on cocaine self-administration in the rat. Brain Res 692:47-56

Callahan PM, Bryan SK, Cunningham KA (1995): Discriminative stimulus effects of cocaine: Antagonism by dopamine D1 receptor blockade in the amygdala. Pharmacol Biochem Behav 51:759-766

Carelli RM, Deadwyler SA (1994): A comparison of nucleus accumbens neuronal firing patterns during cocaine selfadministration and water reinforcement in rats. J Neurosci 14:7735-7746

Carelli RM, Deadwyler SA (1996): Dose-dependent transitions in nucleus accumbens cell firing and behavioral responding during cocaine self-administration sessions in rats. J Pharmacol Exp Ther 277:385-393

Carroll ME, Comer SD (1996): Animal models of relapse. Exp Clin Psychopharmacol 4:11-18

Carroll ME, France CP, Meisch RA (1981): Intravenous selfadministration of etonitazene, cocaine, and phencyclidine in rats during food deprivation and satiation. J Pharmacol Exp Ther 217:241-247

Chang J-Y, Sawyer SF, Lee R-S, Woodward DJ (1994): Electrophysiological and pharmacological evidence for the role of the nucleus accumbens in cocaine self-administration in freely moving rats. J Neurosci 14:1224-1244

Childress AR, McLellan AT, Ehrman R, O'Brien CP (1988): Classically conditioned responses in opioid and cocaine dependence: A role in relapse? In Learning Factors in Substance Abuse, NIDA Research Monograph 94. Washington, DC, US Government Print Office, pp 25-43

Dackis CA, Gold MS (1985): Pharmacologic approaches to cocaine addiction. J Subst Abuse Treat 2:139-145

Davis WM, Smith SG (1976): Role of conditioned reinforcers in the initiation, maintenance and extinction of drug seeking behavior. Pavlovian J Biol Sci 11:222-236

de la Garza R, Johanson CE (1987): The effects of food deprivation on the self-administration of psychoactive drugs. Drug Alcohol Depend 19:17-27

Depoortere RY, Li D-H, Lane JD, Emmett-Oglesby MW (1993): Parameters of self-administration of cocaine in rats: Time course and dose-response determination using a multi-dose method. Drug Alcohol Depend 32:247-256

de Wit H, Stewart S (1981): Reinstatement of cocaine-reinforced responding in the rat. Psychopharmacology 75:134-143

Di Chiara G (1995): The role of dopamine in drug abuse viewed from the perspective of its role in motivation. Drug Alcohol Depend 38:95-137

Ehrman RN, Robbins SJ, Childress AR, O'Brien CP (1992): Conditioned responses to cocaine-related stimuli in cocaine abuse patients. Psychopharmacology 107:523529

Erb S, Shaham Y, Stewart J (1996): Stress reinstates cocaineseeking behavior after prolonged extinction and a drugfree period. Psychopharmacology 128:408-412

Everitt BJ, Cador M, Robbins TW (1989): Interactions between the amygdala and ventral striatum in stimulus-reward associations: Studies using a second-order schedule of sexual reinforcement. Neuroscience 30:63-75

Fontana DJ, Post RM, Pert A (1993): Conditioned increases in mesolimbic dopamine overflow by stimuli associated with cocaine. Brain Res 629:31-39

Fuchs RA, Tran-Nguyen LTL, Specio SE, Groff RS, Neisewander JL (in press): Predictive validity of the extinction/ 
reinstatement model of drug craving. Psychopharmacology

Gawin FH, Kleber HC (1986): Abstinence symptomatology and psychiatric diagnosis in cocaine abusers. Arch Gen Psychiatry 43:107-113

Gerber GJ, Stretch R (1975): Drug-induced reinstatement of extinguished self-administration behavior in monkeys. Pharmacol Biochem Behav 3:1055-1061

Goeders NE, Guerin GF (1994): Non-contingent electric shock facilitates the acquisition of intravenous cocaine self-administration in rats. Psychopharmacology 114: 63-70

Grace AA (1995): The tonic/phasic model of dopamine system regulation: Its relevance for understanding how stimulant abuse can alter basal ganglia function. Drug Alcohol Depend 37:111-129

Gratton A, Wise RA (1994): Drug- and behavior-associated changes in dopamine-related electrochemical signals during intravenous cocaine self-administration in rats. J Neurosci 14:4130-4146

Hiroi N, White NM (1991): The lateral nucleus of the amygdala mediates expression of the amphetamineproduced conditioned place preference. J Neurosci 11: 2107-2116

Hooks MS, Duffy P, Striplin C, Kalivas PW (1994): Behavioral and neurochemical sensitization following cocaine self-administration. Psychopharmacology 115:265-272

Hurd YL, Weiss F, Koob GF, And NE, Ungerstedt U (1989): Cocaine reinforcement and extracellular dopamine overflow in rat nucleus accumbens: An in vivo microdialysis study. Brain Res 498:199-203

Jaffe JH, Cascella NG, Kumar KM, Sherer MA (1989): Cocaine-induced cocaine craving. Psychopharmacology 97:59-64

Kalivas PW, Stewart J (1991): Dopamine transmission in the initiation and expression of drug- and stress-induced sensitization of motor activity. Brain Res Rev 16:223-244

Kiyatkin EA (1995): Functional significance of mesolimbic dopamine. Neurosci Biobehav Rev 19:573-598

Kiyatkin EA, Stein EA (1994): Biphasic changes in mesolimbic dopamine signal during cocaine self-administration. NeuroReport 5:1005-1008

Kosten T, Gawin FH, Silverman DG, Fleming J, Compton M, Jatlow P, Byck R (1992): Intravenous cocaine challenges during desipramine maintenance. Neuropsychopharmacology 7:169-176

McGregor A, Roberts DCS (1993): Dopaminergic antagonism within the nucleus accumbens or the amygdala produces differential effects on intravenous cocaine selfadministration under fixed and progressive ratio schedules of reinforcement. Brain Res 624:245-252

McGregor A, Baker G, Roberts DCS (1994): Effects of 6-hydroxydopamine lesions of the amygdala on intravenous cocaine self-administration under a progressive ratio schedule of reinforcement. Brain Res 646:273-278

Meil WM, See RE (1997): Lesions of the basolateral amygdala abolish the ability of drug associated cues to reinstate responding during withdrawal from self-administered cocaine. Behav Brain Res 87:139-148

Meil WM, Roll JM, Grimm JW, Lynch AM, See RE (1995):
Tolerance-like attenuation to contingent and noncontingent cocaine-induced elevation of extracellular dopamine in the ventral striatum following 7 days of withdrawal from chronic treatment. Psychopharmacology 118:338-346

Neisewander JL, O’Dell LE, Tran-Nguyen LTL, Castaneda E, Fuchs RA (1996): Dopamine overflow in the nucleus accumbens during extinction and reinstatement of cocaine self-administration behavior. Neuropsychopharmacology 15:506-514

Parsons LH, Koob GF, Weiss F (1995): Serotonin dysfunction in the nucleus accumbens of rats during withdrawal after unlimited access to intravenous cocaine. J Pharmacol Exp Ther 374:1182-1191

Paxinos G, Watson LC (1986): The Rat Brain in Stereotaxic Coordinates. New York, Academic Press

Peoples LL, West MO (1996): Phasic firing of single neurons in the rat nucleus accumbens correlated with the timing of intravenous cocaine self-administration. J Neurosci 16:3459-3473

Piazza PV, Deminiere JM, Le Moal M, Simon H (1990): Stress- and pharmacologically-induced behavioral sensitization increases vulnerability to acquisition to amphetamine self-administration. Brain Res 514:22-26

Prasad BM, Sorg BA, Ulibarri C, Kalivas PW (1995): Sensitization to stress and psychostimulants. Involvement of dopamine transmission versus the HPA axis. Ann NY Acad Sci 771:617-625

Preston KL, Sullivan JT, Berger P, Bigelow GE (1993): Effects of cocaine alone and in combination with mazindol in human cocaine abusers. J Pharmacol Exp Ther 267:296307

Ramsey NF, Van Ree M (1993): Emotional but not physical stress enhances intravenous cocaine self-administration in drug naive rats. Brain Res 608:216-222

Robinson TE, Berridge KC (1993): The neural basis of drug craving: An incentive-sensitization theory of addiction. Brain Res Rev 20:247-291

Robinson TE, Camp DM (1991): The feasibility of repeated microdialysis for within-subjects design experiments: Studies on the mesostriatal dopamine system. In Robinson TE, Justice JB (eds), Microdialysis in the Neurosciences. New York, Elsevier, pp 189-234

Satel SC, Krystal JH, Delgado PL, Kosten TR, Chaney DS (1995): Tryptophan depletion and attenuation of cueinduced craving for cocaine. Am J Psychiatry 152:778783

Self DW, Barnhart WJ, Lehman DA, Nestler EJ (1996): Opposite modulation of cocaine-seeking behavior by D1- and D2-like dopamine receptor agonists. Science 271:15861589

Shaham Y (1993): Immobilization stress-induced oral opioid self-administration and withdrawal in rats: Role of conditioning factors and the effect of stress on "relapse" to opioid drugs. Psychopharmacology 111:477-485

Shaham Y, Stewart J (1994): Exposure to mild stress enhances the reinforcing efficacy of intravenous heroin self-administration in rats. Psychopharmacology 114: 523-527

Shaham Y, Stewart J (1995): Stress reinstates heroin-seeking in drug-free animals: An effect mimicking heroin, not withdrawal. Psychopharmacology 119:334-341 
Shaham Y, Klein CC, Alvares K, Grunberg NE (1993): Effects of stress on oral fentanyl consumption in rats in an operant self-administration paradigm. Pharmacol Biochem Behav 46:315-322

Sorg BA, Kalivas PW (1991): Effects of cocaine and footshock stress on extracellular dopamine levels in the ventral striatum. Brain Res 559:29-36

Stewart J (1984): Reinstatement of heroin and cocaine selfadministration behavior in the rat by intracerebral application of morphine in the ventral tegmental area. Pharmacol Biochem Behav 20:917-923

Stewart J, DeWit H, Eikelboom R (1984): The role of unconditioned and conditioned drug effects in the self-administration of opiates and stimulants. Psychol Rev 91:251268

Wallace BC (1989): Psychological and environmental determinants of relapse in crack cocaine smokers. J Subst Abuse Treat 6:95-106

Weiss F, Hurd YL, Ungerstedt U, Markou A, Plotsky PM, Koob GF (1992a): Neurochemical correlates of cocaine and ethanol self-administration. Ann NY Acad Sci 654:220-241

Weiss F, Markou A, Lorang MT, Koob GF (1992b): Basal extracellular dopamine levels in the nucleus accumbens are decreased during cocaine withdrawal after unlimited-access self-administration. Brain Res 593:314-318

Weissenborn R, Yackey M, Koob GF, Weiss F (1995): Measures of cocaine-seeking behavior using a multiple schedule of food and drug self-administration in rats. Drug Alcohol Depend 38:237-246

Whitelaw RB, Markou A, Robbins TW, Everitt BJ (1996): Excitotoxic lesions of the basolateral amygdala impair the acquisition of cocaine-seeking behavior under a second-order schedule of reinforcement. Psychopharmacology 127:213-224

Wise RA, Murray A, Bozarth MA (1990): Bromocriptine selfadministration and bromocriptine-reinstatement of cocaine trained and heroin-trained lever pressing in rats. Psychopharmacology 100:355-360

Wise RA, Yokel RA, Hansson P, Gerber GJ (1977): Concurrent intracranial self stimulation and amphetamine selfadministration in rats. Pharmacol Biochem Behav 7:459 461

Worley CM, Valadez A, Schenk S (1994): Reinstatement of extinguished cocaine-taking behavior by cocaine and caffeine. Pharmacol Biochem Behav 48:217-221 